\title{
Students' Perspectives Toward The Use of Diary As Learning Strategy in English Literary Criticism Subject
}

\author{
Gia Puspita Mokodompit ${ }^{1 *}$ \\ ${ }^{1}$ Department of English Language Studies, Universitas Hasanuddin, Makassar, Indonesia \\ *giamokodompit23@gmail.com
}

\begin{abstract}
This study is aimed to elaborate the students' perspectives toward the use of diary as learning strategy in English Literary Criticism Subject of English Department, Universitas Negeri Gorontalo. The participants of this research are the students of class D that consist of 22 students at the 6th semester in academic year of 2018/2019. Using a qualitative method, the data were obtained from semi structure interview. This study also used Braun and Clarke theory as the technique of analyzing the data. Therefore, questions of interview were adapted and developed from Patton As a result of this research, the students believed that the use of diary can help them in teaching and learning process. Instead of impacting students, this strategy also indirectly provides benefits for the lecturers in the classroom. It is suggested to use a diary for instructional purposes as it can help students in developing their own learning processes and strategies. Besides, the strategy also has some negative impact, such as the lack of understanding new material which makes it difficult for students to learn independently and also some of the students only copied the diary from their friends without discovering and reading the books by themselves. Therefore, the role of the lecturers is very important in the classroom to examine what they have written, to clarify and explain again the materials that are still confusing for the students.
\end{abstract}

Key words: Diary, learning strategy, students' perspective.

\section{Introduction}

In teaching and learning process, teachers and students has become an important means which takes an important role in order to achieve the learning purpose. Teaching process nowadays is focused on the students' participation rather than teacher domination in the classroom [1], it is known as students center. It means that, most of the students are involved and participate in the classroom. However, in teaching and learning process mostly they did not give their participate in the classroom. It can be seen by most of students tend to be passive in the classroom during teaching and learning process. Learning is not a spectator sport. Students do not learn much just by sitting in class listening to teachers, memorizing prepackaged assignments, and spitting out answers. In other words, they must talk about what they learn, write about it, relate it to past experiences, and apply it to their daily lives [2]. Also, they have to make what they learn part of themselves. In order to make them use all of it, indeed learning strategies are the best way to earn it. 
Every person has their own learning strategies to help them in teaching and learning process. Learning strategies are defined as "specific actions, behaviors, steps, or techniques, such as seeking out conversation partners, or giving oneself encouragement to tackle a difficult language task used by students to enhance their own learning"[3]. She proposed a more specific definition of learning strategies which is as specific actions taken by the students to make their learning easier, more enjoyable, more effective, and more transferable to the new situations in the classroom. In order that, when the learners choose the strategy that appropriate with the learning style, this strategy become a useful in teaching and learning process in the classroom. [4] mention that learning strategies are a device used by the students to acquire knowledge. It means that the students can have one or more certain strategies to assist them in acquiring the knowledge that they want to learn. On the other hand, learning strategies can be procedures that facilitate a learning task. [5] state that strategies are most often conscious and goal-driven, especially in the beginning stages of tackling an unfamiliar language task. That is why intellectual people need to have learning strategies or a particular way to understand something more structured.

In English Department as one part of this research object, there are several subjects and topics was given by the lecturers. These subjects consist of skill such as listening, reading speaking and writing along with Grammar, Syntax, Prose, and Literary Criticism. Looking at those subjects of English, there are some obstacles were encountered during the learning process. For instance, in English Literary Criticism Subject. Based on the researcher's experience and preliminary observation in the classroom there are some of students lack of understanding the material. It caused the lecturer was unable to come to the class and they must learn independently. Besides that, they are lack of motivation to read the material based on the topic discussion. Although, the syllabus and teaching material already given to the students. One of the factors that can affect students' failure to demonstrate competent uses of English is lack of interest in learning. In this case, they also lack motivation. Based on this case, the students will be understanding the material if the lecturer has a learning strategy in teaching and learning process.

Therefore, with the existence of diary as a learning strategy, students have their own perspective toward the running process of learning. This perspective is the result of the learning environment influencing their learning process, and to determine the learning outcomes. Moreover, investigating students' perspectives toward the use of diary as learning strategy in English Literary Criticism Subject can gives insight in the extent to which the strategy has been successfully implemented and also provides a positive impact for lecturers such as enhancing the effectiveness and creativity in teaching and learning. Then, for students can build their critical thinking in absorption the material, understanding the context of topic discussion, and evaluation their self during teaching and learning process. likewise, this research will contribute and be helpful for the further researchers.

Based on the explanation above, students' perspective can influence the teaching and learning process. Having students' perspectives is important for both lecturer and students, Because the student will be easier to learn material if they understand their perspective. By knowing own perspective, the students will know their needs and what teaching media is appropriate for them. If the students have a good perspective about a learning strategy that given by the lecturer, it can lead the lecturer and students to achieve a good result from the teaching and learning process. If they have negative perspective to the learning strategy, then the lecturer should modify or change the strategy in order to achieve the learning purpose.

Therefore, this research is required to be conducted in order to explore students' perspectives toward the use of diary as the learning strategy applied in the classroom. In this case, the researcher carries out research with the title 'Students' Perspectives Toward the Use of Diary as Learning Strategy in English Literary Criticism Subject." This research would be conducted in English Department, Letters and Cultures Faculty, Universitas Negeri Gorontalo.

Since the use of diary at English Department, Universitas Negeri Gorontalo has actually been applied by several lecturers as the learning strategy in the classroom. Furthermore, this study is to see what are the students' perspectives toward the use of diary as learning strategy in English Literary Criticism Subject. Therefore, the research question of this study is formulated as follows; "What are students' perspectives toward the use of diary as learning strategy in English Literary Criticism Subject?" This research was expected to give contribution to explore students and the lecturer's knowledge about learning strategy, specifically about the use of diary in the classroom. Then, the students and lecturers can explore more about the use of diary as the learning strategy. Moreover, the research also considered as the reference for those who interested to do a study in the same field. This research aimed to give information to students and lecturers about the implementation of using diary as learning strategy. In addition, this research provided information about the advantages and the disadvantages of using diary, so the lecturer can use or modify the diary as learning strategy the way that the students like in order to make them comfortable to learn and the learning purpose can be reached effectively. Moreover, further researcher can expand this research as source and reference for them who interested in the same point

\section{Theoretical Reviews}




\section{The Concept of Perspectives}

Nowadays, the definition of perspective already presented by many people including experts which is most important to be discussed. Almost everyday people always express their perspectives in various things. Many people said that, perspective is our point of view towards people and things. Mostly, how people perceive something is based on their experience. But the question is how can we be sure that our perspective will be understood by the people? That is why we need with human perspective. According to [6] the aim of perspective is to changes person's or group's attitude or behavior toward some even, idea, object, or other people, by using written or spoken word to give information, feelings, reasoning, or a combination of them.

Therefore, many people in giving their perspective will through those process. Perspective is correlate to human organs. In other words, perspective is an ability to understand the differences of feelings. [7] states that there are three factors that can influence s someone's opinion. First it comes from experience, motivation, and the last is emotional site. People want to interpret their thought based on how far they understand the object as the target or it is called experience.

Furthermore, [8] also confirmed that perspective is person's opinion or view about something to get a value. In this case, perspective is needed in order to improve something from different person's opinion. Therefore, perspective can be determined as an ability to understand the differences of feelings about something.

In relation to the concept of perspective above, this study aimed to see the students' perspectives toward the use of diary as learning strategy in English literary criticism subject. As a learning strategy in teaching and learning process, the process of how students acquiring experience by using diary in their class can influence their point of views and feelings during the teaching and learning process. It is important to figure out students' perspective because it can be a consideration for the teacher in evaluating the process of teaching and learning including diary. Student's perspectives of the implementation of diary is important to understand, because the teacher can see how suitable is the diary for students in teaching and learning process in the classroom.

\section{Definition of Diary}

Diary is a kind of writing that contains theory, explanation, and ideas or personal opinion related to the topic being read. It is almost similar to resume or summary [9]. Diary is one of the kinds strategies that can be used to enforced students to read the teaching material. The main purpose of diary is to make the students ready to learn and to be well prepared [10]. They read the materials earlier before come to class. Thus, it can help them to discuss or to present the theory in front of the class.

Based on the basis of structure, diaries are classified as unstructured, semi-structured, or structured and may also be classified as a log. Unstructured diaries are open-ended and the diarist is given little or no guidance regarding the shape, form, or content that should be included. Structured diaries, in contrast, are very specific regarding these aspects. A semi structured diary contains certain content and then completed by several explanations. Semi structured is similar to structured diaries. However, the semi-structured diary does not have food notes, sub-topic, and sometimes has no conclusions. It only contains what is known and only discusses and explains what is seen as well as logs are diaries with a list or table-like format [11].

Therefore, the type of diary used by this research is a semi-structured diary. A semi structured diary contains certain content and then completed by several explanations. For example, students write their own diary by using different books and different perception or different sources, the ideas in diary will be vary. So, they could discuss each other and explain their own ideas.

\section{The Implementation of Diary in English Literary Criticism Subject}

The use of a diary in English Department, Universitas Negeri Gorontalo has been applied by several lecturers as the learning strategy to improve students' ability in the classroom. This strategy becomes an alternative way for the lecturer in teaching and learning process. It is also implemented as the learning strategy in linguistics and literature especially in English Literary Criticism Subject.

The diary was able to help students to be well prepared before come to classroom, particularly in English Literary Criticism subject. Some steps can be implemented for the diary strategy, including:

- Students are given the learning syllabus of English Literary Criticism that they will learn or discuss in each meeting.

- Students are demanded to compose a diary about the topic that will be discussed.

- This diary will be submitted before or after class, which then will help them during the learning process or discussion time.

- The lecturer will begin to ask students' understanding regarding to the material and the students will give feedback through their responses and statements based on what they have written in their diary. 
- Students will be given time to share their opinions with their friends in classroom.

\section{Learning Strategis}

Learning strategies are a device used by students to acquire knowledge [12].Furthermore, [13] described learning strategies as some steps taken by students to enhance their own learning. Then she proposed a more specific definition of learning strategies which is as specific actions taken by the students to make their learning easier, faster, more enjoyable, more self-directed, more effective, and more transferable to new situations.

Consequently, every student has their own ways to catch and understand the lesson. Therefore, it is necessary for the students to discover several ideas to help them in the learning process. One of the ideas is by finding an appropriate learning strategy.[14] suggested to use a diary for instructional purposes it can help students develop their own learning processes and strategies. On that ground, this diary can be the learning strategy that can be used by students to write the material that given by the lecturer. This can be a strategy for students to overcome the difficulties when they are trying to write something more structured. This strategy also automatically can help the students understand and remember the material.

Learning strategies are defined as "specific actions, behaviors, steps, or techniques, such as seeking out conversation partners, or giving oneself encouragement to tackle a difficult language task used by students to enhance their own learning" [15].

\section{Methodology}

\section{Research Method}

This research is focused on students' perspective towards the use of Diary as Learning Strategy in English Literary Criticism Subject. In order to satisfy the objectives and answer the questions of the research the qualitative method will be used. Qualitative research is concerned with qualitative phenomena, i.e., phenomena relating to or involving quality or kind [16]. He also describes on his study the example of qualitative research is the way to investigate the reason of human behavior such as why people think or do certain things.This method is appropriate to use because qualitative research can analyze the various factor which motivate people to behave in a particular manner or which make the people like or dislike a particular thing.

\section{Site}

This research would be conducted at English Department, Letters and Culture Faculty, Universitas Negeri Gorontalo. It was considered an appropriate site based on several reasons. Firstly, this research will select students who had enrolled English Literary Criticism to be the participants regarding the research question. Secondly, there was only one class that implemented diary as the learning strategy in English Literary Criticism subject. This research would be conducted when the subject has been finished, in which the data were taken when students have passed the subject. It means that this research explores students' perspective based on their experience when using the diary in the sixth semester.

\section{Participant}

The participant of this research were the students of English Department on sixth semester in academic years 2018/2019 who had enrolled English literary criticism subject that used diary. In addition, there were 5 classes in this semester; each class consisted of 20 to 25 students. However, the participants of this research were only those who applied a diary as the learning strategy in English literary criticism subject. Therefore, to determine the appropriate participants for this research, the researcher conducted a preliminary observation. This was done because it provided some information and the background of the situation related to the respondents' perspective on the use of a diary as the learning strategy in English literary criticism subject. Furthermore, based on the results of previous observation, there was only one class applying a diary as their learning strategy in class. As a result, class D consisting of 22 students became the participants of this research because this class had met the criteria.

\section{Technique of Collecting the Data}

Interviewing the research participants is one and only technique of collecting the data for this research. [17] states that Interviewing provides the researcher a means to gain a deeper understanding of how the participant interpret a situation or phenomenon. The aims are usually an authentic understanding of people's experience. So, it is required to find out their perspectives toward the use of diary in classroom. This research was used written interview by link 
platform, the link would be share to all of participants in order to get the answer about their perspective toward the use of diary in English Literary Criticism Subjects. Moreover, this research provides the list of questions that related to the use of diary in English Literary Criticism subject in English Department students. Therefore, the interview used in this research is Semi Structure Interview. [18] have divided interview in three parts, namely Structure Interview, Semi- Structure Interview, and Unstructured Interview. By using semi structure interview, the interviewees and interviewer will be more flexible in expressing their opinions and ideas. Furthermore, There are some reasons why this research conducted by written interview. First based on the preliminary observation there are some participants did not feel comfortable when the researcher conducting face to face interview, thus affecting the participant's answer. Second, nowadays there is a virus called Covid-19 which has been spread in a whole world. This kind of case make all countries in the world especially Indonesia had to close their areas and applied work from home system. This situation make the researcher and participants should be stayed in the home and doing all of things through online system. From that situation the researcher conduct this research through online system.

\section{Technique of Analyzing The Data}

To analyze the data of this study, a thematic analysis will be used. "Thematic analysis is the method for identifying, analyzing and reporting patterns (themes) within the data". The goal of thematic analysis is to identify themes, pattern in the data that are important or interesting and this theme can be used to say something about an issue [19]. In addition, this research was used[20] 6-step framework to analyze the data. This step was chosen because the steps were arguably the most influential approach and it offered a clear and usable framework for doing the thematic analysis.

\section{Findings and Discussion}

\section{Findings}

Students gave some variety of perspectives about the use of Diary as Learning Strategy in English Literary Criticism Subject. Interview quote represented as evidence to support findings of the research. Additionally, some of participants answer the question of interview in Indonesia, and to display the data the researcher provides the answer of participant in English. Furthermore, the table below summarizes the students' perspectives into six categories, namely; Implementation of diary, Diary advantages, Diary disadvantages, Obstacles of using diary, independent learning and Suggestion about the use of diary.

Table 1. Codes and Themes

\begin{tabular}{ll}
\hline Codes & Themes \\
\hline A good strategy in learning process & Implementation of diary \\
Very helpful in reading and writing skill & \\
As supporting system & Diary advantages \\
Can help students to be more prepared & \\
Get many information & \\
Make students more active in classroom & Diary disadvantages \\
Do plagiarism from another student's diary & \\
Students feels bored & \\
Spent much time in presenting in front of the class & Obsta les of using diary \\
Do not have Internet data to search material & \\
Hard to Understand many sources of material & \\
Misunderstanding the material of topic discussion & Independent Learning \\
Can help to learn independently & \\
Can be memorized indirectly & \\
Students will read the Important Things & \\
The use of diary in classroom should be used in a good way \\
The diary can be modified or make more attractive \\
The diary should be apply in another subject
\end{tabular} \begin{tabular}{l} 
\\
\hline
\end{tabular}




\section{Discussion}

In this section, the findings of this study are discussed, with reference to the relevant literature. The English Department students' perspectives on the use of diary as learning strategy in English literary criticism subject were presented. The aim of this topic is to describe students' perspectives toward the use of diary as learning strategy in English literary criticism subject.

Furthermore, this study found that there are six themes with various perspectives about students' perspectives toward the use of diary as learning strategy in English Literary Criticism Subject.They are Implementation of diary, Diary advantages, Diary disadvantages, Obstacles of using diary, Independent learning, and Suggestion about the use of diary. In the following paragraphs, each of these themes is explained.

\section{Implementation of diary}

Implementation of diary mean this strategy is useful for student especially during teaching and learning process in the classroom. The existence of diary as learning strategy in order to make the students to be well prepared before come to class. As a result, diary has been well implemented as learning strategy in English Literary Criticism Subject. The implementation of this strategy is generally welcomed very positively by the students. Most of the students are strongly agree that diary can help them in classroom especially in discussion session. Furthermore, the existence of diary as a learning strategy, students have their own perspective toward the running process of learning.

As explained in the previous study by [21], the implementation of this strategy is providing a new teaching style for lecturers of linguistics, especially syntax, and it is a very useful strategy to help students learn in class. For instance, it may assist students in accepting materials, adding insight and knowledge of students related to the material being taught, making students more well-prepared and more active in class or group discussion, and also motivating students in the classroom learning. Therefore, based on all of students' perspective about the implementation of diary in English literary criticism subject most of students agreed that the use of diary has some benefits in the classroom. By using this strategy can create effective atmosphere during teaching and learning process and also through this strategy the students can be an active learner. Those are supported by [22] learning strategies are defined as "specific actions, behaviors, steps, or techniques, such as seeking out conversation partners, or giving oneself encouragement to tackle a difficult language task used by students to enhance their own learning". She proposed a more specific definition of learning strategies which is as specific actions taken by the students to make their learning easier, more enjoyable, more effective, and more transferable to new situations. In other word, when the learners choose the strategy that appropriate with the learning style, these strategies become a useful in teaching and learning process.

\section{Diary Advantages}

The second identified theme is diary advantages. Diary advantages mean learning process in the use of diary is useful for student especially during teaching and learning process in the classroom. The use of this strategy will make them motivate to learn because the way the lecturer applicant it is really simple and can be understood easily by them.

[23] support this research finding as she stated that the advantages of diary itself is considered strongly motivating them to be well-prepared before attending the class, and this makes them more passionate about learning the material the day before the syntax class begins. Meanwhile, in this research found that the existence of diary as learning strategy in order to make students to be well prepared before come to class.

Almost every student reported that the use of diary in classroom can give some advantages for the students, for example, students more prepare to study because they already read the material before the class. In other words, they have a preparation and prior knowledge before class begin. Also, they can get more information from many sources related to the topic that will be discussed. Thus, the advantages of using diary are students can be active in the classroom, they can share their opinion about the topic discussion and also students center learning can exist in the classroom.

\section{Diary Disadvantages}

Disadvantages of diary is the third identification of theme. However, all of the participants have their own perspective regarding to the disadvantages when diary was applied in classroom. Additionally, this study found that there are three responses mostly said by them regarding to the diary disadvantages, firstly, do plagiarism from other students' diary, secondly students feel bored, and thirdly spent much time in presenting diary in front of the class. By seeing several answers of participant, the researcher found that the use of diary in the classroom it would be depends on the teaching style that used by the lecturer, so that can be affected to their teaching and learning process in the classroom.

Furthermore, related to the explanation above, this study found there are three responses mostly said by participants regarding to the diary disadvantages. First, it has been explained by some participants. For example, some of students said the disadvantages of using diary is the students can be easily copied the diary from their friends. In this case, the role of lecturer is needed in implementation of this strategy. This can be performed by collecting students' diaries every time they come to the class, asking their understanding first and then asking questions about 
the material that students have not understand yet. Then, in learning process the students sometimes feel bored for waiting their friends when present their diary in front of the class, they said it is spent much time. In order to overcome some of obstacles above, the lecturer should be managing the time in teaching and learning process better.

Therefore, the role of lecturers is needed in which the lecturers should take full responsibility for the implementation of this strategy, that is by collecting students' diary in every beginning of the learning process, asking their comprehension regarding the material. After that, lecturers are explaining and clarifying students' understanding if they are wrong in choosing the theory or understanding of a student who does not comply with material intended.

\section{Independent Learning}

Independent learning is the fifth of identified theme. The use of diary for students in any condition that may influence their independent learning. Additionally, there are three responses mostly said by them regarding to the independent learning, firstly, can help students to learn independently, secondly the material can be memorized indirectly, and thirdly the existence of diary in classroom the students will read the important things.

The diary can make the students study at home or before the class begins. They can prepare the material as soon as possible when the discussion or learning takes place, and this is very helpful for lecturers in the learning process for students already prepare it before the class begins. Lecturers also no longer need a lot of time in explaining the material.

For example, before come to class the students more prepare to study because they already read the topic material. Through the analysis of the data from students' perspectives, this strategy was applied in classroom caused by several conditions and situations. First, the students have lack motivation to read the material based on topic discussion. Second, if the lecturer was unable to come so they can learn independently. Third, to make students to be well prepared before come to class. It is known that writing the diary becomes a requirement of students before attending the class, and it should be written based on the outline of the material to be discussed in the following week.

Moreover, this strategy can help students and lecturer in teaching and learning process. For instance, it may assist students in accepting materials, adding insight and knowledge of students related to the material being taught, making students more well-prepared and more active in class or group discussion, and also motivating students in the classroom learning, especially if lecturers are unable to come to the class and students are required to study independently. Besides, the diary is required for students to compose or as a requirement for students before attending the class. Furthermore, students generally consider this strategy an opportunity to participate in the advancement of education and the positive impact will contribute to the success of students' learning either inside or outside the classroom. It is said that learning strategy is a procedure that can facilitate students' assignments. Consequently, this strategy can make student have prior knowledge before attending the class. Based on this situation, the lecturer takes the alternative way which is applied diary as learning strategy to make the students get better understanding about the material, and also students would be more active to share their opinion and build critical thinking during class discussion.

Furthermore, the role of lecturers is needed in which the lecturers should take full responsibility for the implementation of this strategy, that is by collecting students' diary in every beginning of the learning process, asking their comprehension regarding the material. After that, lecturers are explaining and clarifying students' understanding if they are wrong in choosing the theory or understanding of a student who does not comply with material intended.

\section{Suggestion About The Use of Diary}

The last identified theme is the suggestion about the use of diary. Many students perceive that the use of diary in the classroom can be applied in another subject because they believe this strategy is a good way for lecturers and students to helpful during teaching and learning process. Additionally, there are three responses mostly said by them regarding to the suggestion about the use of diary, firstly, the use of diary should be used in a good way, secondly the diary can be modified or make more attractive, and thirdly most of students suggest that diary should be apply in another subject. However, most of students also perceive that the diary should be use in a good way. Because some of students composed their diary when they just arrived at class. Then, students suggest that the content of diary can be modify or make more attractive in order to overcome students bored. As a result, the students can be more active and students center learning can exist in the classroom.

However, by considering positive responses from all participants regarding to the implementation of diary they argued that diary should be applied in English Department particularly to the lecturers who teach another subject. This assumption is revealed by their self-perspectives based on the experience while using diary. They said this strategy can give them multiple benefits so it would be better diary is applied by all the lecturer just like what has done. All participants in this research considered the use of diary as learning strategy will be a good tool in case of make student to be well prepared before come to the class.

Thus, based on the research findings the researcher can conclude that, indirectly all participant admitted they agree using diary as learning strategy in English Literary Criticism Subject. The result showed that based on their experience who have used for their classroom have procured the positive influences such as to be well prepared, get many information, make students active in the classroom. It is because, in using diary they always enjoy. The reason 
why the participant enjoys in using diary are diary is pretty much easy to do, train students to be well prepared before come to the class, so they can have prior knowledge.

Furthermore, the students possible to face some difficulties in using diary as learning strategy in the classroom. It also cannot be separated from the role of lecturers in the classroom, which lecturers make the class more fun and comfortable for students. For instance, students will be more active in the classroom when they have a preparation before come to class. Consequently, one week before class begin the students have to search or found some material that related to topic discussion. As a result, when the class begin, they have a prior knowledge or information regarding to the topic discussion and it became the students will be more active to share their opinion each other.

Moreover, to make the students more active in the classroom become the strongest reason of the lecturer in applied this strategy. [24] suggested some solution to increase students' participation in the classroom. One of his solutions is keep them (students) busier than you are (teacher). In the traditional teaching process, usually the teacher/lecturer is only sitting or stand in the front of the room, and sometimes speaks and explain the teaching material in lower voice. Unconsciously, it makes students bored especially who sit at the back of the classroom. Related to this problem, he suggested making the students busier than the teacher/lecturer. As a result, the class would be more active. Everyone in the class takes part and become active to share their opinions and build their critical thinking. In instance, the lecturers can give and ask the students to read the learning material first before coming to class, so they will know the content of learning material or the topic discussion that they will learn. As a result, the learning purpose can be achieved.

\section{Conclusion}

This study was carried out at English Department, Faculty of letters and culture, Universitas Negeri Gorontalo, in class D on sixth semester in academic year 2018/2019 in English Literary Criticism Subject. A qualitative method was adopted in order to collect the data. Also, thematic analysis was used to analyze the data and grouping into theme. Based on the result of analyzing data interview, this study successfully answered the research question by finding six themes associated with the perspectives about the use of Diary as Learning Strategy in English Literary Criticism Subject. Namely; Implementation of diary, Diary advantages, Diary disadvantages, Obstacles of using diary, Helped independent learning and Suggestion about the use of diary.

Consequently, the diary has been well implemented as a learning strategy. It is proved by several perspectives of students regarding the case where it has a positive impact for students' activity in the classroom.Instead of impacting students, this strategy also indirectly provides benefits for the lecturers in the classroom. Although, the strategy still has many obstacles during the implementation, it was considered by the disadvantages of diary that the students got during the existence of diary as learning strategy in their classroom.

However, when the lecturer explains learning material, not all of students can understand well about the material. So that the lecturer always asked students to compose their diary about the material that will be discussed. As a result, the diary become the alternative way for lecturer to make all of students understand. And also, the aims of the diary itself is to make a students have a prior knowledge before come to the class, so they can build their critical thinking during class discussion.

Furthermore, all students that have been implemented this strategy reveal that the strategy is very motivating them in the classroom because they become more prepare when coming to the class. It also gives prior knowledge for them because the lecturers will ask some questions to them when they come to the class, and the diary can help them to deal with it. Therefore, the role of lecturers is needed in which the lecturers should take full responsibility for the implementation of this strategy, that is by collecting students' diary in every beginning of the learning process, asking their comprehension regarding the material. After that, lecturers are explaining and clarifying students' understanding regarding to the topic discussion.

\section{References}

[1] F. Muhamad, 'Increasing Students' Readiness and Competencies in Learning Process through Intellectual Diary(ID)", English Education Study Program, Letters and Culture Faculty, Gorontalo State University, 2014

[2] Chikering and Gamson, "Seven Principles for Good Practice in Undergraduate Education",Washington Center News Fall, 1987.

[3] R. L. Oxford, 'Language Learning Style and Strategies", 2003.

[4] J. Rubin, What the "Good language learner" can teach us. TESOL Quarterly, 9(1), 41-51, 1975.

[5] A. U.Chamot, 'Language learning strategy instruction: Current issues and research".Annual Review of AppliedLinguistics, Cambridge: Cambridge University Press, 2005. 
[6] DL. A.Nihe, 'The Students'Perspective on The Use Of Self Access Center" English Department, Faculty of Lettersand Culture,Gorontalo State University, 2015.

[7] Y. Nopu, 'Using Personal Vocabulary Notes (PVN) in Mastering Vocabulary: A Study on Students Perception"English Department, Faculty of Letters and Culture, Gorontalo State University, 2017

[8] L. A.Nihe, ' The Students' Perspective on The Use Of Self Access Center" English Department, Faculty of Lettersand Culture,Gorontalo State University, 2015.

[9] F. Muhamad, 'Increasing Students' Readiness and Competencies in Learning Process through Intellectual Diary(ID)", English Education Study Program, Letters and Culture Faculty, Gorontalo State University, 2014

[10] F. Muhamad, 'Increasing Students' Readiness and Competencies in Learning Process through Intellectual Diary(ID)", English Education Study Program, Letters and Culture Faculty, Gorontalo State University, 2014

[11] L.Sheble and B.Wildemuth, 'Research Diaries. Application of social research methods to questions in information and library science. Santa Barbara, CA: LibrariesUnlimited, 2009

[12] J. Rubin, What the "Good language learner" can teach us. TESOL Quarterly, 9(1), 41-51, 1975

[13] R. L. Oxford, 'Language learning strategies: What every teacher should know”, Baston,Massachusetts: Heinle \& Heinle Publisher, 1990.

[14] A. U.Chamot, 'Language learning strategy instruction: Current issues and research".Annual Review of AppliedLinguistics, Cambridge: Cambridge University Press, 2005

[15] R. L. Oxford, 'Language Learning Style and Strategies", 2003

[16] C. R.Kothari, "Research Methodology”. New Age International. ISBN (13) 978-81-224-2488-1, 2004.

[17] A.Kurnia,'Manajemen Penelitian", 2011.

[18] P. D. Sugiyono, 'Memahami Penelitian Kualitatif", Bandung: Alfabeta, 2010

[19] V. Braun and V. Clarke, Using thematic analysis in psychology.Qualitative Research in Psychology, 3(2), 77-101.ISSN 1478-0887, 2006.

[20] V. Braun and V. Clarke, Using thematic analysis in psychology.Qualitative Research in Psychology, 3(2), 77-101.ISSN 1478-0887, 2006.

[21] M.A.Tuahunse, 'Students' perception on the using of diary as learning strategy of syntax course"EnglishDepartment, Faculty of Letters and Culture, Gorontalo State University, 2018

[22] R. L. Oxford, 'Language Learning Style and Strategies", 2003.

[23] M.A.Tuahunse, 'Students' perception on the using of diary as learning strategy of syntax course"EnglishDepartment, Faculty of Letters and Culture, Gorontalo State University, 2018.

[24] K. Haynes, 'Top 12 Ways to Increase Student Participation", 2014. 